\title{
Tumor treating fields therapy is feasible and safe in a 3-year-old patient with diffuse midline glioma H3K27M — a case report
}

\author{
Hanna Gött ${ }^{1} \cdot$ Silke Kiez ${ }^{2} \cdot$ Hildegard Dohmen $^{3} \cdot$ Malgorzata Kolodziej $^{1} \cdot$ Marco Stein $^{1}$
}

Received: 26 November 2021 / Accepted: 24 January 2022 / Published online: 18 February 2022

(c) The Author(s) 2022

\begin{abstract}
Since high grade gliomas are aggressive brain tumors, intensive search for new treatment options is ongoing. For adult patients with newly diagnosed (ndGBM) and recurrent glioblastoma (rGBM), low intensity intermediate frequency alternating electric fields, known as tumor treating fields (TTFields) have been established as a new treatment modality. Tumor treating fields significantly increase survival rates in combination with adjuvant temozolomide (TMZ) in adult and GBM patients. Here, we report about feasibility and safety of treatment on a pediatric patient with diffuse midline glioma who is receiving TTFields therapy in combination with temozolomide.
\end{abstract}

Keywords Glioblastoma · Glioma · Diffuse midline glioma · TTFields · Pediatric glioma

\section{Introduction}

High-grade gliomas (HGG) are aggressive brain tumors affecting both children and adults [1]. Treatment options are limited in pediatric HGG patients, and prognosis is fatal. Tumor treating fields (TTFields) are low-intensity, intermediate frequency $(200 \mathrm{kHz})$ alternating electric fields used as a treatment for adult GBM [1].

Preclinical models demonstrated that TTFields inhibit proliferation of cancer cells by disruption of the mitotic spindle apparatus resulting in mitotic delay or cell death $[2,3]$; furthermore, they impair DNA-repair-mechanisms and increase chemosensitivity through the induction of cell permeability as well as an increase of autophagy $[4,5]$. Also, an influence on migratory capacity and antitumor immunity has been described [6]. Efficacy and safety of TTFields in adult ndGBM were examined in the phase 3 study EF-14 ( $n=695)$, which demonstrated that the addition of TTFields to maintenance temozolomide (TMZ) significantly prolonged overall survival (OS) $(20.9$ vs $16.0, p<0.001)$

Hanna Gött

Hanna.goett@neuro.med.uni-giessen.de

1 Department of Neurosurgery, University Hospital Giessen, Giessen, Germany

2 Department of Pediatric Hematooncology, University Hospital Regensburg, Regensburg, Germany

3 Institute of Neuropathology, University Hospital Giessen, Giessen, Germany and progression-free survival (PFS) (6.7 vs 4.0 months, $p<0.001$ ) [7]. A subgroup analysis of the EF-14 patient cohort showed that patient compliance (therapy usage) was prognostic for improved survival [8]. Therefore, it is important to maintain high daily/monthly compliance to the TTFields treatment.

For the pediatric population, there are several reports on the use of TTFields. For instance, Branter J. et al. showed efficacy of TTFields on pediatric GBM, medulloblastoma and ependymoma cell lines in vitro [9]. Toledano H. et al. report on 5 pediatric patients (age 11.1-17.7 years at diagnosis) und conclude that TTFields is safe and feasible in children as young as 11 years [10]. Wölfl W. et al. presented 3 patients (age 7, 9, and 11 years) suffering from HGG [11]. Post-marketing surveillance data on TTFields collected for glioma patients $<18$ years of age $(n=30)$ revealed no unexpected adverse events. The most frequently reported adverse events were skin reactions [12].

\section{Case report}

The 3-year-old male patient presented with a tumor located pontine on the right occipital region (Fig. 1a). Stereotactic biopsy was performed, and with the brain tumor classifier employing genome wide DNA- methylation analysis [13], the diagnosis of a diffuse midline glioma H3K27M (calibrated Score 0.98) without MGMT-promoter methylation was obtained. Molecular sequencing detected a HIST1H3B mutation (H3.1 K27M) (Fig. 2). H3.1 and H3.2 K27M 
mutations are typically found in DIPGs and are associated with a better prognosis than the H3.3 K27M-wildtype [14-16].

The patient received radiochemotherapy with TMZ followed by TTFields therapy in combination with maintenance TMZ. Due to the location of the tumor, the infratentorial transducer array layout was used for TTFields application. The infratentorial layout was not yet available during the EF-14 study, and therefore not examined in a clinical setting, but a computer simulation-based study showed the feasibility of TTFields in treating tumors in infratentorial regions [17].

Initially, the patient and his family needed time to get used to the TTFields therapy and due to the usage of TTFields therapy was comparably low during the first month. However, the TTFields usage rate improved every month from about $40 \%$ in the first 2 months to about $80 \%$ after 5 and 6 months (Fig. 3). After the initial time for adaptation to the therapy, the average usage rate in months 4 to 8 was $75.87 \%$, which is above the independent prognostic threshold of $75 \%$ [11]. One year after the initial biopsy, the MRI showed distinct radiological response to the therapy (Fig. 1b). Unfortunately, 1 month later, the patient's general health condition declined, causing reduced usage rates towards the end of
Fig. 2 Histological features of a diffuse malignant pleomorphic glioma, H\&E. Immunohistochemistry stained sections; tumor cells with GFAP expression and upregulation of VEGFR2. Nuclear H3K27Mand ATRX-Expression and high KI67 labeling (a). Copy number profile of diffuse midline glioma H3K27M mutant with a deletion of PTEN gene and especially a loss of chromosome 10 (b). t-SNE analysis showing DNA-methylation clustering of our case in the DMG K27 cohort $(n=78)(\mathbf{c})$. The data basis for the t-SNE evaluation are the 2801 methylome analyzes from Capper et. al. 2018. The 34,000 most variable positions are extracted from these and, together with the data record to be classified, these are reduced in their complexity using t-distributed neighbor embedding (t-SNE). The function was taken from the R - package R-t-SNE by Jesse Krijthe

TTFields therapy. These results demonstrate that even a very young patient is able to adapt to using the TTFields therapy. The patient was on TTFields therapy for almost 9 months and no therapy-related adverse events were observed.

\section{Discussion}

Treatment options for pediatric patients diagnosed with HGG are limited and there is a high need to extend the therapeutic repertoire. TTFields are currently only approved for
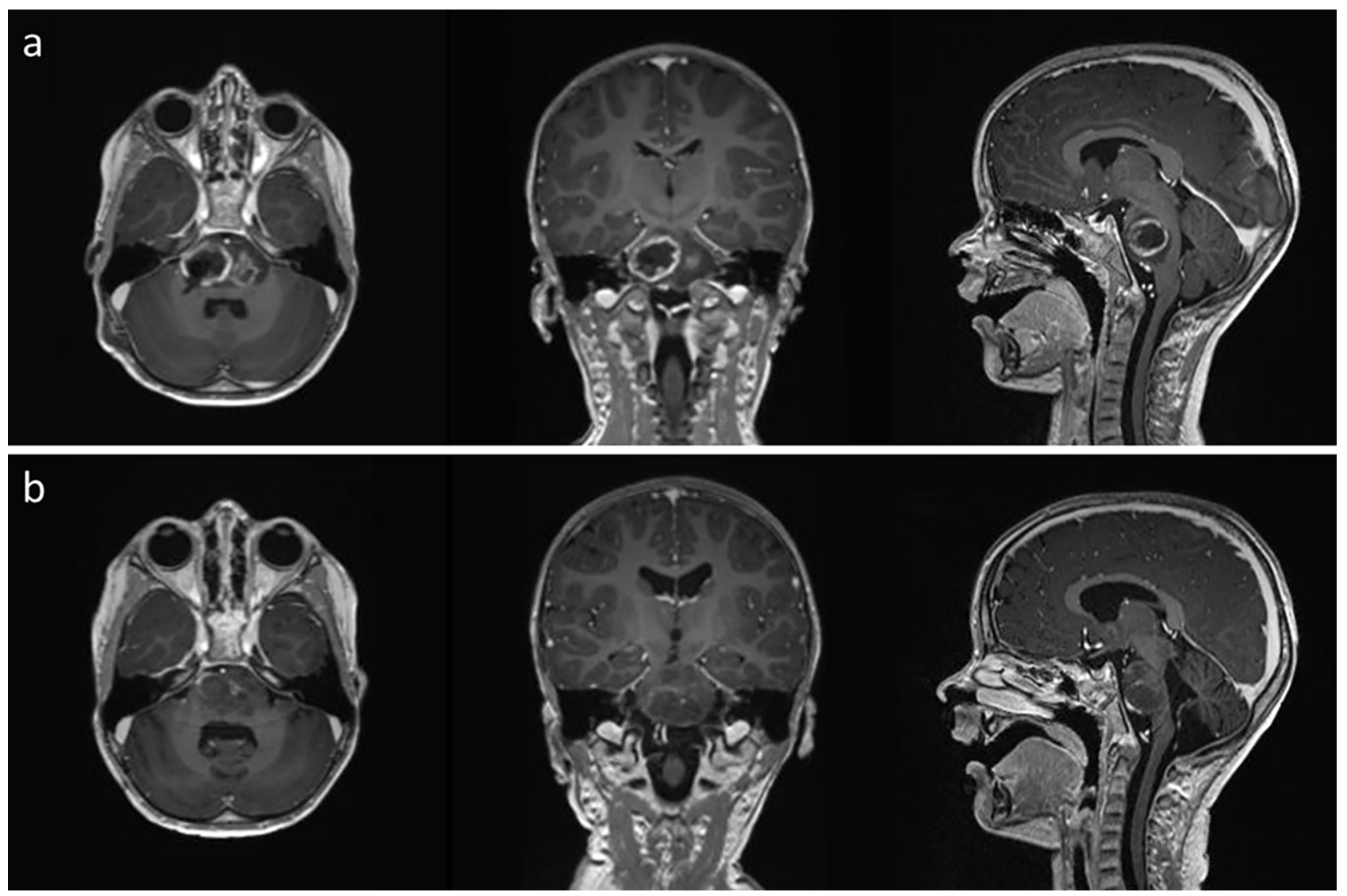

Fig. 1 a Glioma with central necrotic area in the brainstem after stereotactic biopsy by an infratentorial approach. b The same lesion 1 year after biopsy followed by chemoradiation with TMZ maintenance and TTFields therapy. 
a
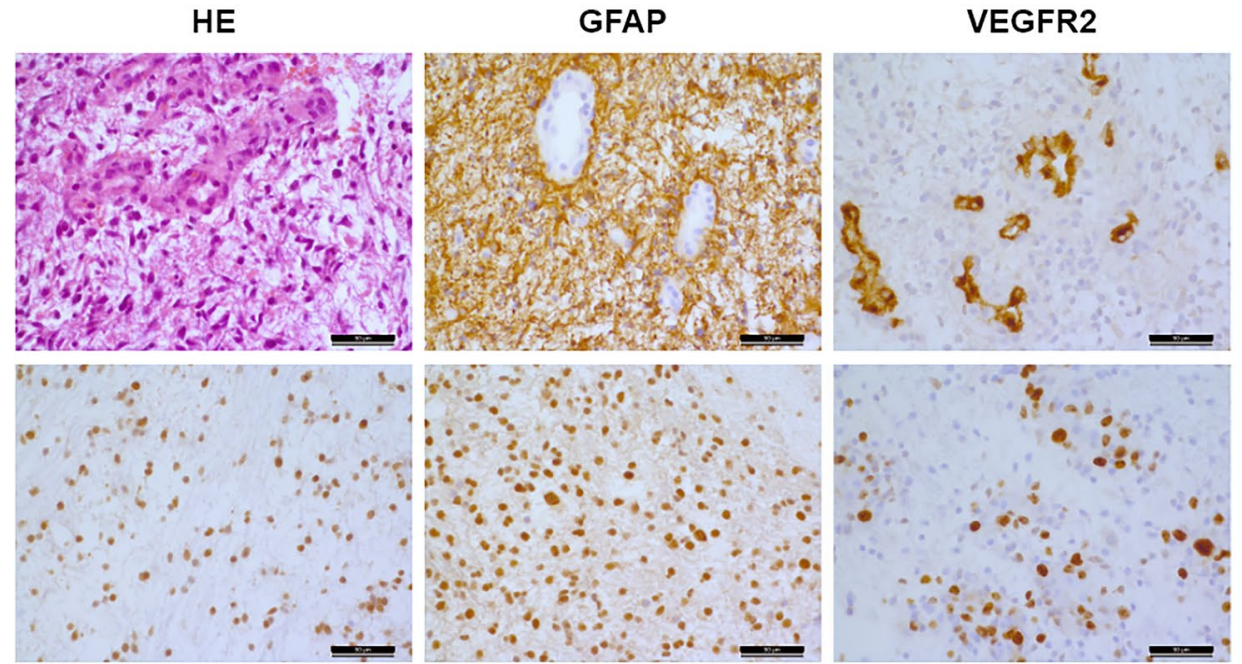

H3K27M

ATRX

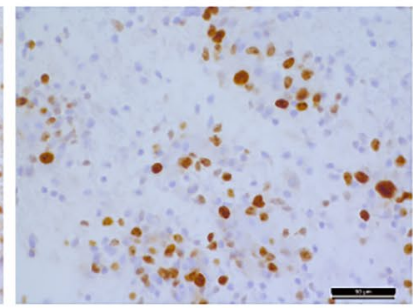

b

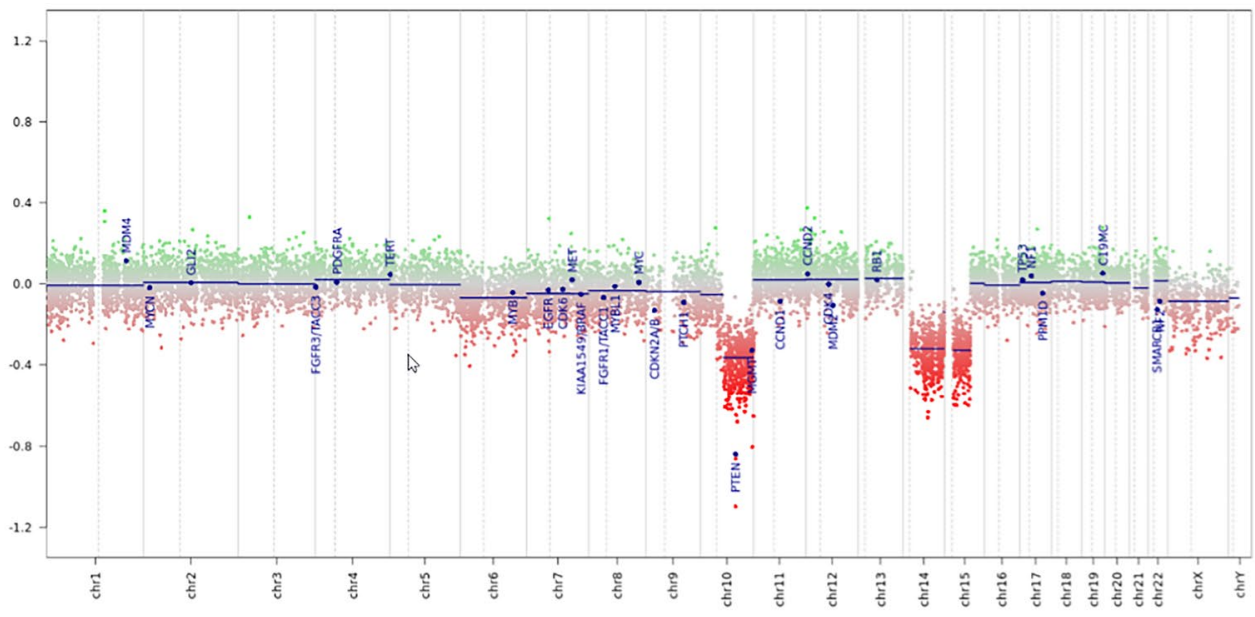

C

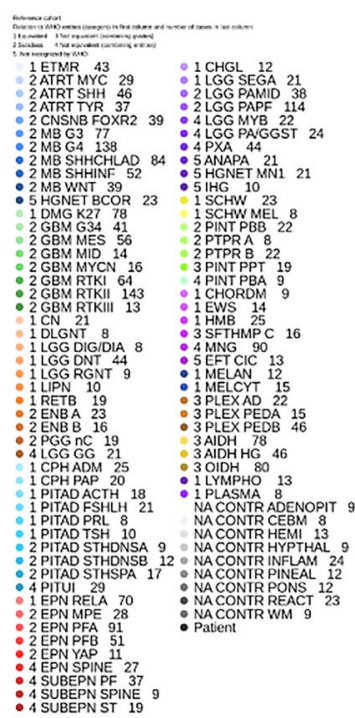

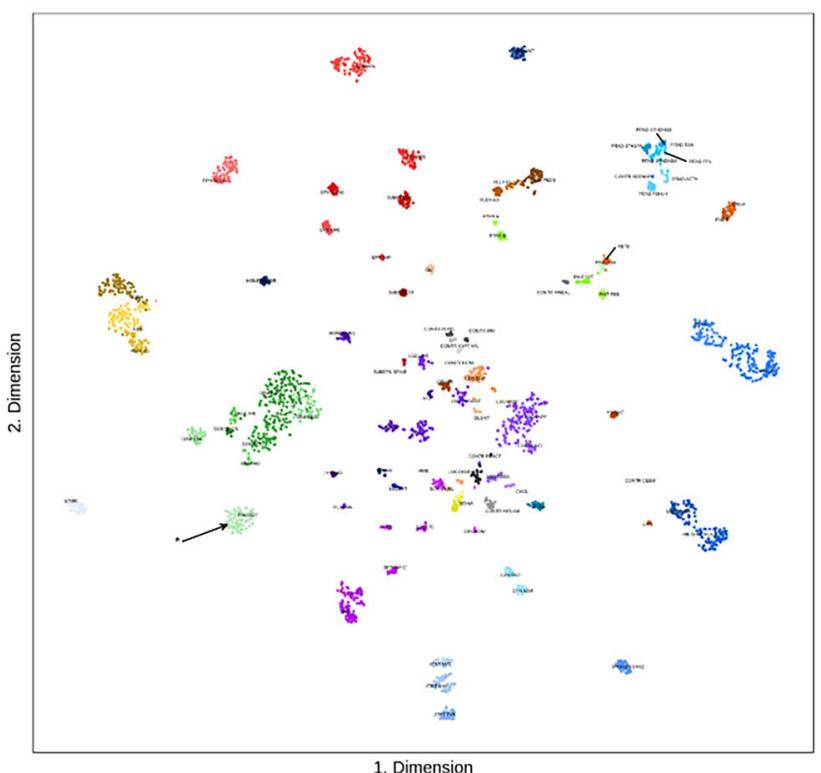


Fig. 3 Average monthly TTFields usage rate in percentage over time. Therapy adherence to TTFields started at a low level and increased strongly within the first 4 months, showing that after an initial adaption period, high TTFields usage rates are also achievable in very young patients. Due to general decline in patient's health state, the usage rate was reduced from month eight

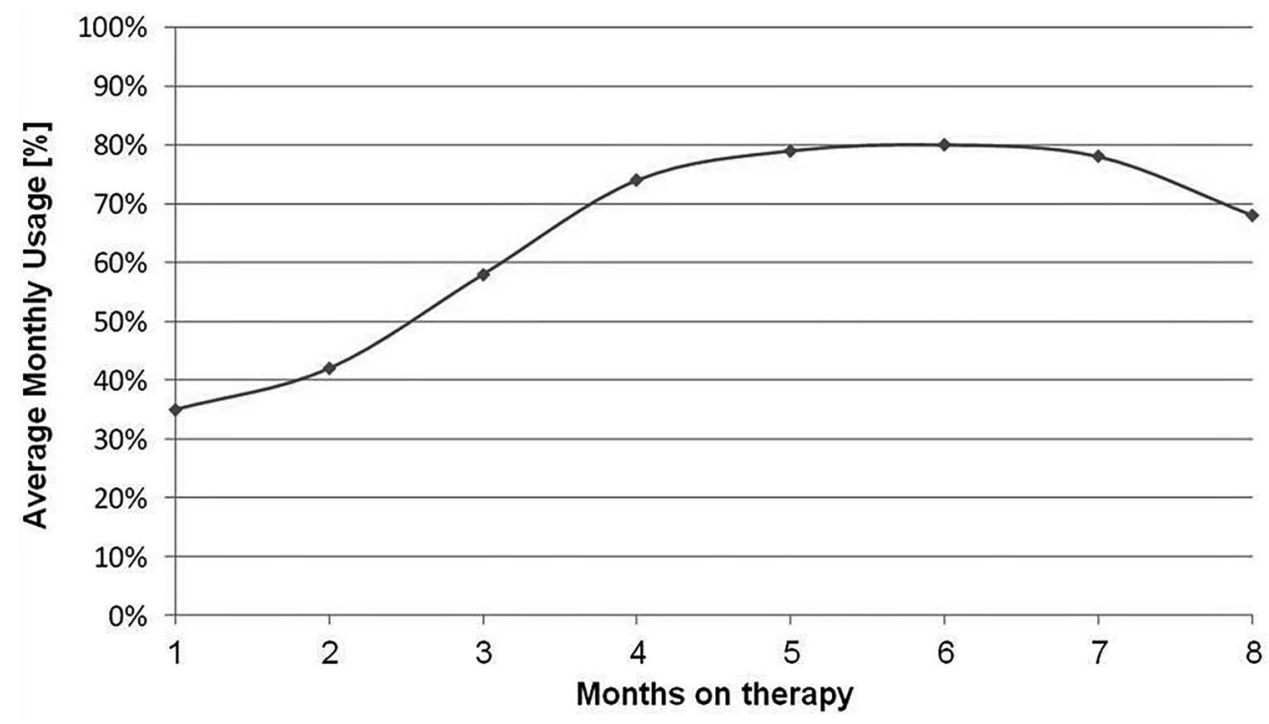

adult glioblastoma. However, there are various reports and ongoing trials on TTFields therapy applied to pediatric glioma patients [11, 18-20] (NCT03033992, NCT03128047). These reports are supported by post-marketing surveillance data that revealed no unexpected adverse events upon TTFields application in pediatric patients [21].

Based on available evidence, we decided in accordance with the family to apply TTFields therapy to a 3-year-old patient diagnosed with diffuse midline glioma. Before initiation of TTFields therapy, we had to determine whether it is possible to fit all four transducer arrays to the patient's head as provided by the array layout. Due to the infratentorial layout provided for the patient, proper placement of the transducer arrays was feasible. In ongoing TTFields trials, the minimal head circumference for placement of transducer arrays was calculated to be $44 \mathrm{~cm}$ (NCT03033992, NCT03128047).

Another critical factor for TTFields treatment is the usage rate achieved by the patients. A subgroup analysis of the EF-14 phase 3 trial demonstrated that OS was extended when the usage rate was $>50 \%$, and there was a trend for extended OS with higher usage rates. In addition, a monthly usage rate of $\geq 75 \%$ vs $<75 \%$ (TTFields plus TMZ arm) was an independent predictor of OS.

Because of these results, it is important to openly discuss the factor usage with patients/caregivers and provide guidance. It was shown before that it might take some time to adapt to the treatment [22]. In the case of a young child, depending on age, it might be more challenging to explain the necessity of a particular treatment scheme. However, as shown in Fig. 3, we found that the patient was quickly able to adapt to the treatment as shown by the steep increase in usage above the independent prognostic threshold of $75 \%$ [8]. This case clearly demonstrates that adherence to TTFields therapy can be continuously improved over time, even if the usage rate might be low in the beginning. When the usage rate is not satisfying initially, TTFields therapy does not have to be terminated, instead patient and caregiver should be encouraged and supported to improve therapy adherence over time as demonstrated in the presented case.

\section{Conclusion}

In summary, TTFields therapy was feasible and safe in a pediatric patient 3 years of age at initiation of therapy. Safety and efficacy in pediatric patients are and will be further investigated in clinical trials.

Funding Open Access funding enabled and organized by Projekt DEAL.

\section{Declarations}

Conflict of interest The authors declare no competing interests.

Open Access This article is licensed under a Creative Commons Attribution 4.0 International License, which permits use, sharing, adaptation, distribution and reproduction in any medium or format, as long as you give appropriate credit to the original author(s) and the source, provide a link to the Creative Commons licence, and indicate if changes were made. The images or other third party material in this article are included in the article's Creative Commons licence, unless indicated otherwise in a credit line to the material. If material is not included in the article's Creative Commons licence and your intended use is not permitted by statutory regulation or exceeds the permitted use, you will need to obtain permission directly from the copyright holder. To view a copy of this licence, visit http://creativecommons.org/licenses/by/4.0/. 


\section{References}

1. Ostrom QT, Cioffi G, Gittleman H, Patil N, Waite K, Kruchko C, Barnholtz-Sloan JS (2019) CBTRUS statistical report: primary brain and other central nervous system tumors diagnosed in the United States in 2012-2016. Neuro Oncol 21(Supplement_5):v1-v100

2. Giladi M, Schneiderman RS, Voloshin T, Porat Y, Munster M, Blat R, Sherbo S, Bomzon Z, Urman N, Itzhaki A et al (2015) Mitotic spindle disruption by alternating electric fields leads to improper chromosome segregation and mitotic catastrophe in cancer cells. Sci Rep 5:18046

3. Kirson ED, Gurvich Z, Schneiderman R, Dekel E, Itzhaki A, Wasserman Y, Schatzberger R, Palti Y (2004) Disruption of cancer cell replication by alternating electric fields. Cancer Res 64(9):3288-3295

4. Giladi M, Munster M, Schneiderman RS, Voloshin T, Porat Y, Blat R, Zielinska-Chomej $\mathrm{K}$, Hååg $\mathrm{P}$, Bomzon Z, Kirson ED, Weinberg U, Viktorsson K, Lewensohn R, Palti Y (2017) Tumor treating fields (TTFields) delay DNA damage repair following radiation treatment of glioma cells. Radiat Oncol 12(1):206

5. Shteingauz A, Porat Y, Voloshin T, Schneiderman RS, Munster M, Zeevi E, Kaynan N, Gotlib K, Giladi M, Kirson ED, Weinberg U, Kinzel A, Palti Y (2018) AMPK-dependent autophagy upregulation serves as a survival mechanism in response to tumor treating fields (TTFields). Cell Death Dis 9(11):1074

6. Rominiyi O, Vanderlinden A, Clenton SJ et al (2021) Tumour treating fields therapy for glioblastoma: current advances and future directions. Br J Cancer 124:697-709

7. Stupp R, Taillibert S, Kanner A, Read W, Steinberg D, Lhermitte B, Toms S, Idbaih A, Ahluwalia MS, Fink K et al (2017) Effect of tumor-treating fields plus maintenance temozolomide vs maintenance temozolomide alone on survival in patients with glioblastoma: a randomized clinical trial. JAMA 318(23):2306-2316

8. Toms SA, Kim CY, Nicholas G, Ram Z (2019) Increased compliance with tumor treating fields therapy is prognostic for improved survival in the treatment of glioblastoma: a subgroup analysis of the EF-14 phase III trial. J Neurooncol 141(2):467-473

9. Branter J, Estevez-Cebrero M, Grundy R, Basu S, Smith S (2017) PDTM-26. Tumor treating fields (TTFields) have anti-proliferative effects on pediatric brain tumor cell lines at clinically deliverable field settings. Neuro-Oncology 19(suppl_6):vi195-vi195

10. Toledano H, Campino GA, Dvir R, Postovsky S, Yalon M (2018) INNV29. Experience with TTFields (OPTUNE ${ }^{\circledR}$ ) in pediatric high grade glioma patients in Israel. Neuro-Oncology 20(suppl_6):vi144-vi144

11. Wölfl M, Miller E, Eyrich M, Krauss J, Schlegel PG (2017) PDCT-07. Tumor treating fields for pediatric patients with high grade glioma: first case series in Germany. Neuro-Oncology 19(suppl_6):vi185-vi185

12. Hanson D (2018) PDCT-11. Surveillance data demonstrates the tolerability of tumor treating fields in pediatric glioma patients. Neuro-Oncology 20(suppl_6):vi202-vi202

13. Capper D, Jones DTW, Sill M, Hovestadt V, Schrimpf D, Sturm D, Koelsche C, Sahm F, Chavez L, Reuss DE, Kratz A, Wefers AK, Huang K, Pajtler KW, Schweizer L, Stichel D, Olar A, Engel NW, Lindenberg K, Harter PN, Braczynski AK, Plate KH, Dohmen H, Garvalov BK, Coras R, Hölsken A, Hewer E, Bewerunge-Hudler M, Schick M, Fischer R, Beschorner R, Schittenhelm J, Staszewski O, Wani K, Varlet P, Pages M, Temming P, Lohmann D, Selt F, Witt H, Milde T, Witt O, Aronica E, Giangaspero F, Rushing E, Scheurlen W, Geisenberger C, Rodriguez FJ, Becker A, Preusser M, Haberler C, Bjerkvig R, Cryan J, Farrell M, Deckert M, Hench J, Frank S, Serrano J, Kannan K, Tsirigos A, Brück W, Hofer S, Brehmer S, Seiz-Rosenhagen M, Hänggi D, Hans V, Rozsnoki S, Hansford JR, Kohlhof P, Kristensen BW, Lechner M, Lopes B, Mawrin C, Ketter R, Kulozik A, Khatib Z, Heppner F, Koch A, Jouvet A, Keohane C, Mühleisen H, Mueller W, Pohl U, Prinz M,
Benner A, Zapatka M, Gottardo NG, Driever PH, Kramm CM, Müller HL, Rutkowski S, von Hoff K, Frühwald MC, Gnekow A, Fleischhack G, Tippelt S, Calaminus G, Monoranu CM, Perry A, Jones C, Jacques TS, Radlwimmer B, Gessi M, Pietsch T, Schramm J, Schackert G, Westphal M, Reifenberger G, Wesseling P, Weller M, Collins VP, Blümcke I, Bendszus M, Debus J, Huang A, Jabado N, Northcott PA, Paulus W, Gajjar A, Robinson GW, Taylor MD, Jaunmuktane Z, Ryzhova M, Platten M, Unterberg A, Wick W, Karajannis MA, Mittelbronn M, Acker T, Hartmann C, Aldape K, Schüller U, Buslei R, Lichter P, Kool M, Herold-Mende C, Ellison DW, Hasselblatt M, Snuderl M, Brandner S, Korshunov A, von Deimling A, Pfister SM (2018) DNA methylation-based classification of central nervous system tumours. Nature 555(7697):469-474

14. Sturm D, Witt H, Hovestadt V, Khuong-Quang DA, Jones DT, Konermann C, Pfaff E, Tönjes M, Sill M, Bender S, Kool M, Zapatka M, Becker N, Zucknick M, Hielscher T, Liu XY, Fontebasso AM, Ryzhova M, Albrecht S, Jacob K, Wolter M, Ebinger M, Schuhmann MU, van Meter T, Frühwald MC, Hauch H, Pekrun A, Radlwimmer B, Niehues T, von Komorowski G, Dürken M, Kulozik AE, Madden J, Donson A, Foreman NK, Drissi R, Fouladi M, Scheurlen W, von Deimling A, Monoranu C, Roggendorf W, Herold-Mende C, Unterberg A, Kramm CM, Felsberg J, Hartmann C, Wiestler B, Wick W, Milde T, Witt O, Lindroth AM, Schwartzentruber J, Faury D, Fleming A, Zakrzewska M, Liberski PP, Zakrzewski K, Hauser P, Garami M, Klekner A, Bognar L, Morrissy S, Cavalli F, Taylor MD, van Sluis P, Koster J, Versteeg R, Volckmann R, Mikkelsen T, Aldape K, Reifenberger G, Collins VP, Majewski J, Korshunov A, Lichter P, Plass C, Jabado N, Pfister SM (2012) Hotspot mutations in H3F3A and IDH1 define distinct epigenetic and biological subgroups of glioblastoma. Cancer Cell 22(4):425-437

15. Mackay A, Burford A, Carvalho D, Izquierdo E, Fazal-Salom J, Taylor KR, Bjerke L, Clarke M, Vinci M, Nandhabalan M, Temelso S, Popov S, Molinari V, Raman P, Waanders AJ, Han HJ, Gupta S, Marshall L, Zacharoulis S, Vaidya S, Mandeville HC, Bridges LR, Martin AJ, Al-Sarraj S, Chandler C, Ng HK, Li X, Mu K, Trabelsi S, Brahim DH, Kisljakov AN, Konovalov DM, Moore AS, Carcaboso AM, Sunol M, de Torres C, Cruz O, Mora J, Shats LI, Stavale JN, Bidinotto LT, Reis RM, Entz-Werle N, Farrell M, Cryan J, Crimmins D, Caird J, Pears J, Monje M, Debily MA, Castel D, Grill J, Hawkins C, Nikbakht H, Jabado N, Baker SJ, Pfister SM, Jones DTW, Fouladi M, von Bueren AO, Baudis M, Resnick A, Jones C (2017) Integrated molecular metaanalysis of 1,000 pediatric high-grade and diffuse intrinsic pontine glioma. Cancer Cell 32(4):520-537

16. Castel D, Philippe C, Calmon R, Le Dret L, Truffaux N, Boddaert N, Pagès M, Taylor KR, Saulnier P, Lacroix L, Mackay A, Jones C, Sainte-Rose C, Blauwblomme T, Andreiuolo F, Puget S, Grill J, Varlet P, Debily MA (2015) Histone H3F3A and HIST1H3B K27M mutations define two subgroups of diffuse intrinsic pontine gliomas with different prognosis and phenotypes. Acta Neuropathol 130(6):815-827

17. Levi S, Naveh A, Bomzon Ze, Kirson ED, Weinberg U (2017) EXTH-76. optimizing transducer array configuration for treating tumors in the infratentorial and supratentorial brain using tumor treating fields (TTFields). Neuro-Oncology 19(suppl_6):vi89-vi89

18. Green AL, Mulcahy Levy JM, Vibhakar R, Hemenway M, Madden J, Foreman N, Dorris K (2017) Tumor treating fields in pediatric high-grade glioma. Childs Nerv Syst 33(7):1043-1045

19. Crawford J, Dhall G, Margol A, Saria M, Kesari S (2016) NIMG-66. Clinical experiences of tumor treating fields (TTFields) in pediatric patients with GBM. Neuro-Oncology 18(suppl_6):vi139-vi139

20. O'Connell D, Shen V, Loudon W, Bota DA (2017) First report of tumor treating fields use in combination with bevacizumab in a pediatric patient: a case report. CNS Oncology 6(1):11-18 
21. Kinzel A, Perez S, Stindl J, Grewal J, Kirson E (2018) OS5.5 Surveillance data demonstrates the tolerability of tumor treating fields in pediatric glioma patients. Neuro-Oncology 20(suppl_3):iii225-iii225

22. Onken J, Goerling U, Heinrich M, Pleissner S, Krex D, Vajkoczy P, Misch M (2019) Patient reported outcome (PRO) among highgrade glioma patients receiving TTFields treatment: a two center observational study. Front Neurol 10:1026
Publisher's Note Springer Nature remains neutral with regard to jurisdictional claims in published maps and institutional affiliations. 